\title{
Changes of narrative meaning-making markers during the different phases of breast cancer treatment for women below 50 years old
}

\begin{abstract}
BACKGROUND
The onset of breast cancer is considered a potential traumatic event associated with physical and psychological effects, in particular when it occurs at the age below 50 . The literature lacks a longitudinal narrative exploration of breast cancer experience of young women.
\end{abstract}

\section{PARTICIPANTS AND PROCEDURE}

Using the narrative device as a diachronic tool aimed at promoting semiotic connection processes during the different phases of the therapeutic path, the authors constructed an ad hoc narrative interview to explore the meaning-making processes of 10 breast cancer patients below 50 years old during three turning-point phases: prehospitalization (T1); postoperative counseling (T2); and adjuvant therapy (T3). The research took place at National Cancer Institute Pascale of Naples. Through an ad hoc qualitative methodology, this study identifies the prevailing modes with which the five narrative meaning-making functions are articulated in the repeated narrative during the three phases.

\section{RESULTS}

The findings capture the patterns of change of narrative meaning-making markers during the illness experience, highlighting both integrated modes of connections between aspects of experience over time and moments of block in specific critical phases for women under 50 .

\section{CONCLUSIONS}

From a clinical health psychology point of view the results suggest the promotion of integration between the synchrony of the medical path and the diachrony of the subjective experience of women to support resources for adapting to experience.

\section{KEY WORDS}

breast cancer; trauma experience; narrative; meaningmaking; medical treatments; turning-point phases; women under fifty; clinical implications

ORGANIZATION - 1: University of Naples Federico II, Naples, Italy · 2: Clinical Psychology Unit, National Cancer Institute "Fondazione G. Pascale", Naples, Italy · 3: Breast Surgery, National Cancer Institute "Fondazione G. Pascale", Naples, Italy

AUthors' Contributions - A: Study design - B: Data collection - C: Statistical analysis - D: Data interpretation .

E: Manuscript preparation · F: Literature search · G: Funds collection

CORReSPONDING AUthor - Maria Luisa Martino, University of Naples Federico II, Corso Umberto I 40, 80138 Naples,

Italy, e-mail: marialuisa.martino@unina.it

to Cite this ARTICle - Martino, M. L., Lemmo, D., Gargiulo, A., Barberio, D., Abate, V., Avino, F., \& Freda, M. F. (2022).

Changes of narrative meaning-making markers during the different phases of breast cancer treatment for women

below 50 years old. Health Psychology Report, 10(1), 58-67. https://doi.org/10.5114/hpr.2021.105363

RECEIVED 11.03.2021 · REVIEWED 15.03.2021 · ACCEPTED 17.03.2021 · PUBLISHED 13.04.2021 


\section{BACKGROUND}

The onset of breast cancer before the age of 50 potentially indicates a traumatic and critical event that shatters a woman's life, with physical and psychological consequences that seem to acquire specific characteristics in terms of impact and adaptation to illness in a phase of life characterized by important achievements (Lemmo et al., 2020).

To date, epidemiological studies highlight that in the last 15 years, breast cancer has affected 2.4 million women, with the highest incidence in the age group 34-49 years (IHME, 2018), in which a survival rate of $87 \%$ is attested.

So women below 50 years old who have breast cancer are more vulnerable targets exhibiting specific needs and clinical aspects that cannot be overlapped with data present in the literature, which is mainly focused on women over 50 years of age (Cordova et al., 2007).

Women below 50 years old often receive more aggressive breast cancer diagnoses and treatments, which destroy their daily life and their own visions of the world (Goula et al., 2020). The type of surgery (mastectomy or quadrantectomy) and even more the effects of medical and drug treatments have physical and psychological sequelae regarding body image, loss of fertility and early menopause, sexuality, and interactions with partners and children (Bolton \& Isaacs, 2018; Helms et al., 2008). Also the difficulties of psychological adaptation and the risk of major traumatic outcomes (Cordova et al., 1995) derive from a stronger fear of recurrence and health anxiety (Jones et al., 2014).

The literature highlights the chances for young women to experience growth during illness, transforming the negative emotions into resources and modifying their life priorities (Di Giacomo et al., 2016).

Therefore, the psychological trauma, which may occur as a result of such a severely distressing event, starts at the onset of illness, which has characteristics of intangibility and chronicity (hereditary or possible relapse) (Gurevich et al., 2002), and continues during the different phases of treatment. Every medical phase is constituted as a turning point of the protocols related to medical treatment, and at the same time, they reflect psychological turning points of the meaning of the relationship with illness over time.

Within a socio-constructivist and semiotic perspective (De Luca Picone, 2020a, b; Salvatore, 2016; Valsiner, 2014), these experiences affect the basic elements that regulate the relationship between the internal and external worlds (Janoff-Bulman, 2004; Joseph \& Linley, 2005) and interrupt the continuity over time, creating a crisis in the meaning-making processes that support their personal life story and continuity of life (Brockmeier, 2000; Martino et al., 2019a; Neimeyer,
2006; Rasmussen \& Elverdam, 2007). This imposes the narrative urgency on the mind and activates the search for a new synthesis of meanings (Esposito et al., 2017; Rainone et al., 2017; Santaniello et al., 2020).

The literature lacks a narrative and semiotic exploration of breast cancer experience in young women, which is able to shed light on the narrative processes of meaning-making of their experience in the specific phases of the therapeutic pathway.

In a previous study (Martino et al., 2019c), we identified specific modes of narrative functioning in women below 50 years old in the initial phase of the onset of the disease. This objective is not achieved in the literature in longitudinal and diachronic terms, highlighting the way in which the repetition of the narrative in the different phases of the disease makes it possible to identify the changes of the narrative modalities related to the meaning-making process of breast cancer at the age below 50 over time in order to create personalized support practices.

\section{NARRATIVE DEVICE AND MEANING-MAKING FUNCTIONS}

Starting from the narrative literature and our previous study in the context of illness (Martino et al., 2019a), we believe that narration is an elective tool for the construction of meaning-making processes (Neimeyer et al., 2010) of the experience and the reconfiguration of time perspectives (Brockmeier, 2000) both during and after the illness (Gillies \& Neimeyer, 2006; Hall, 2011; Waters et al., 2013) aimed at supporting adaptation, integration of the event construction of resources, well-being, and active coping strategies (Angus \& McLeod, 2004; Martino et al., 2019b, c; Neimeyer, 2006; Quattropani et al., 2017).

In particular, we believe that "repeated narrative" (Smorti \& Fioretti, 2016) in the course of time disambiguates the meanings of the event, integrating the negative aspects into a self-schema (Pennebaker et al., 1997). Thus, narration establishes semiotic connection processes between the different aspects and plans of experience. These processes can be considered transformative (McAdams, 2008) in their discursive tendency towards the search for a configuration able to build meaning, even if temporarily, to the experience of illness (Greenberg et al., 1993).

Here, we highlight the five key functions that constitute the narrative process of breast cancer experience.

By the term function, we mean the process that allows information to be manipulated at multiple levels and to respond to the ever-changing demands of the environment, processes that are essential for the individual's adaptation in support of mental health (Bion, 1962; Piaget, 1964; Winnicott, 1945). Starting from the mentioned literature, we highlight the five
Narrative and breast cancer 
Maria Luisa

Martino,

Daniela Lemmo,

Anna Gargiulo,

Daniela Barberio,

Valentina Abate,

Franca Avino,

Maria Francesca

Freda key functions that define the process of semiotic connection, as a sense-making process aimed at connecting different objects of reality, among the different objects of the experience, which all constitute the fundamental aspects of adaptation and coping with the BC experience (De Luca Picione et al., 2019). Therefore, the narrative functions represent different ways of functioning of narrative thought (Bion, 1962; Martino et al., 2019c):

Organization of temporality. Narration constructs connections that are primarily spatial and temporal, assuming for the subject a function of orientation of their existence. This refers to connections and insertion of elements of the story within a spatial and temporal framework. It allows a person to organize cancer experience by subjectively connecting different temporal plans of the experience; moreover, narration allows one to bring together, in a tridimensional way (past-present-future), the different lines of time (Brockmeier, 2000; Martino et al., 2019c).

Search for meaning. This function refers to the connections in the interpretation of the event, finding a meaning in the world in the face of a traumatic

\section{Table 1}

Socio-demographic characteristics of women

\begin{tabular}{|c|c|}
\hline Women & $\begin{array}{l}\text { All participants } \\
\qquad(N=10)\end{array}$ \\
\hline Age & $M=44.40$ years \\
\hline \multicolumn{2}{|l|}{ Educational level } \\
\hline Primary and middle school & 5 \\
\hline High school & 4 \\
\hline Degree & 1 \\
\hline \multicolumn{2}{|l|}{ Job position } \\
\hline Housewife/unemployed & 6 \\
\hline Employee & 3 \\
\hline Self employed & 1 \\
\hline \multicolumn{2}{|l|}{ Marital status } \\
\hline Single & 1 \\
\hline Married & 7 \\
\hline Divorced & 2 \\
\hline \multicolumn{2}{|l|}{ Number of children } \\
\hline Three & 1 \\
\hline Two & 7 \\
\hline One & 2 \\
\hline Children's age & $M=14.60$ years \\
\hline
\end{tabular}

Note. Data are reported as number of patients. event, rebuilding shattered assumptive worldviews, and constructing connections of sense between continuity and discontinuity (Bonanno et al., 2004; JanoffBulman, 2004). In other words, this function refers to the searching for the causes of the illness due to the need to know "Why me?" and what relationship, including prospective, can be created between oneself and the experience of the onset of cancer (Sherman \& Cohen, 2006).

Emotional regulation. This refers to the narration process as a dynamic multilevel system that can regulate the relation between emotion and thought and the connections between emotion and event. The narrative device allows a process of labeling emotions and realizing the important roles that these emotions play in certain events. The narration process is an opportunity to label the emotions and connect them to events in light of the present.

The connection between emotion and event, mediated by the narrative device, establishes the basis and containment for processes of emotional regulation (Tronick, 2011) and meta-reflects on the new version of the experience.

Organization of self-other relationship. This refers to the organization of connections between the self and the world, between oneself and external worlds, and between oneself and others. Narration becomes a device for sharing with others, organizing and reorganizing relationship plans in their different aspects and roles (Rimè, 2009).

Orientation to action. This refers to the relation between oneself and the action meant to cope with illness. This function is the narrative construction of the ability to make decisions and choices and undertake behaviors that impact events. Narration is, therefore, an open and dynamic process of construction, regulation, and transformation of its own agency (Martino et al., 2019c; Brockmeier, 2009).

Within a longitudinal theory-driven research design, in this study, we identify the ways in which the aforementioned functions are articulated within three turning-point phases of the crossing of the experience of breast cancer by women below 50 years old: pre-hospitalization (T1); postoperative counseling (T2); and adjuvant therapy (T3). In phase I - facing the unknown - the woman is still undergoing diagnostic investigation of a suspected nodularity. In phase II - impact of the critical valence of the disease - the woman has learned about the severity of her pathology (receiving histological examination), has undergone surgery for malignant nodularity, and decides the therapeutic path to be taken. In phase III - relationship with a changed body identity - the woman is faced with postoperative chemotherapy or radiotherapy treatments that affect her relationship with her body.

This study gives the opportunity to observe how the construction of these different connections 
can vary in the three phases considered as turning points, highlighting the trajectories of the narrative functions of women below 50 years old in the most critical phases of their course of treatment of the disease, thus identifying the type of changes that the repeated narration promotes and supports in the meaning-making process of illness, with the aim of building personalized support for women below 50 years old with breast cancer and for their needs (Villani et al., 2016).

\section{PARTICIPANTS AND PROCEDURE}

\section{PARTICIPANTS AND DATA COLLECTION}

The research was conducted at the National Cancer Institute "Fondazione G. Pascale," Naples, which is the national reference for the treatment and care of neoplastic illness, and in the frame of STAR Programme, financially supported by UniNA and Compagnia di San Paolo. The research was co-constructed in collaboration with the hospital's psychology service and breast unit surgery and approved by the medical committee of the National Cancer Institute. The hospital's psychology service has provided its location and facilities for monitoring meetings and taking charge of women who wanted to continue with the psychotherapeutic support over time.

The authors presented the aim of the research and the request of participation in collaboration with the psychologist of the hospital. The women eligible for the research were telephoned to explain the start of the research and the aims. Following the telephone call we left the women time to decide and confirm whether or not during the next medical meeting would take place in the hospital. The women who took part in this research were identified from medical reports and qualified according to the following criteria:

Eligibility criteria: First access to the hospital before the age of 50; no genetic tests conducted before the onset of the cancer; voluntary participation.

Exclusion criteria: Metastatic disease (stage IV); psychotherapeutic treatments in progress. The recruitment of the women was conducted through a 1-day meeting in the hospital to explain the whole path and the aim of the research.

Women's participation was voluntary; they provided informed consent, and the privacy policy was approved by the hospital. We recruited 10 women below 50 years old $(M=44.40)$ during the pre-hospitalization phase (T1: 40-60 days before surgery) and then we met them again during the postoperative counseling phase (T2: 30-40 days after surgery), that is when the women received the response of the histological examination and during the adjuvant therapy phase (T3: 25-35 days after the start of ther- apy), which can be differentiated into chemotherapy, radiotherapy, and hormone therapy.

\section{NARRATIVE $A D$ HOC INTERVIEW}

We constructed an ad hoc narrative interview termed the Early Breast Cancer-Processing Trauma Interview (EBC-PTI) for the exploration of meaning-making processes of young women with traumatic breast cancer experience (Martino et al., 2019c) in every phase of their therapeutic path.

The narrative interview, repeated in $\mathrm{T} 1, \mathrm{~T} 2$, and T3, involved nine open questions related to the five main areas of illness experience. Each question was intended as a narrative prompt able to open a construction of sense following the aforementioned meaning-making functions in every phase of undergoing the experience. The five main areas of illness experience are as follows: story of experience; hypothesis on the causes of cancer and relationships with similar experiences; episodic deepening; specific criticality and change; and resources.

The interview was constructed to activate different ways of declining narrative discourse. There is alternation between questions that open up episodic narratives (e.g., I would like you to choose three words/adjectives/idioms that come to mind when thinking about this phase of the experience. There is a particular event/ episode to which you relate when she says... We are interested in knowing, what happened, where she was, who else was with her, what she felt, what she thought at the time) and semantic narratives (e.g., People sometimes imagine or have ideas about why they got sick. Do you have any idea about it or imagine something?), thus activating the different narrative functions as modes of functioning of narrative thinking.

The questions are ordered to allow a gradual immersion in the critical experience, opening, in the final parts, a space for dialog on resources and changes (e.g., Could you tell me if there is someone or something that you have felt to be particularly helpful? How? With whom do you find yourself talking about it? Of our meeting... Could you tell me if there is one thing in particular that you feel you can draw from going through this phase?). The interview was conducted in an ad hoc room of the hospital; it has an average duration of approximately $45 \mathrm{~min}$ and was recorded and then transcribed verbatim. The interview was conducted by two women psychologists who are experts in clinical psychology and narrative methodology. The same gender membership has represented a key point to promote the narrative of women. The researchers were young women; this allowed them to construct an empathic and exchange relationship with the patients.

The interview had an average duration of approximately $45 \mathrm{~min}$ and was recorded and then transcribed verbatim.
Narrative and breast cancer 


\section{ANALYSIS APPROACH}

According to a qualitative narrative approach aimed at the in-depth analysis of the meaning-making processes (Salvatore \& Valsiner, 2011), we created an ad hoc methodology. Using a theory-driven methodology, we start from the five narrative functions to observe the process of narrative articulation when the time of illness experience changes.

We identified the narrative segment of text attrib-
Maria Luisa Martino, Daniela Lemmo, Anna Gargiulo, Daniela Barberio, Valentina Abate, Franca Avino, Maria Francesca Freda utable to different narrative functions, and then we attributed an interpretative label for each identified segment in order to define the different modes of functioning. In the case of the segment of text attributable to different narrative functions the authors, after a discussion with the independent judges, decided to insert the segment into different functions.

Through the criterion of redundancy, which is a mode that must return at least one case in more than half of the women (6 women), we identified the prevailing ways in which women below 50 years old articulate the narrative functions that represent the universe of signification of our target of interest. The modal redundancies of these functions have been presented and read in their diachronic evolution as the three times vary in order to grasp the narrative changes during the progress of the experience.

Analyses were conducted with the help of three independent judges who are experts in the qualitative analysis of texts and who individually identified the different modes.

\section{RESULTS}

We illustrate for each narrative function the pattern of changes among the redundant modes with respective exemplary narrative segments:

- Organization of temporality presents this pattern of changes among the redundant modes:

(T1) Chronicled mode $\rightarrow$ (T2) Reconstructive mode $\rightarrow$ (T3) Reconstructive mode.

In $\mathrm{T} 1$, at the beginning of the experience, and therefore at the onset of the disease, we identify a chronicled mode. The narration confines a temporality characterized by the chronicle of medical times, ordering the visits and offering a micro-analytical succession of medical tasks and practices.

I went to get a breast scan, then early in the day I underwent a mammogram because they had already realized that there was something wrong, and then the day after I underwent aspiration and even before the aspiration, the doctor said it was not good (id. 2).

In the transition to the second phase, this mode becomes a reconstructive mode. We begin to create links between the events that have happened up to that point. Next to the temporal dimension is the weaving of the spatial dimension, thus favoring the construction of a three-dimensional scheme, more complex because intertwined with subjective dimensions of continuity and with other levels of life. More extensive and less restricted spaces and times appear in the narratives, including body space. External spaces and other spaces of the medical institution are intertwined: the room of the admission and the places where the wound is treated. A distinction is made in terms of post-surgery time, where the common denominator is given by the waiting.

In February, I learned that it was a cancer that needed to be removed. They gave me an approximate date involving between 40 and 60 days of waiting. We were hospitalized on a Friday, so on Saturday and Sunday, my roommates and I started to digest this thing. Then, after surgery, I had to wait for the histological report. In the meantime, the surgeons said that I would have to do the medication myself. Then, I went back to school in the last days (id. 6).

At T3, the redundant mode is always a reconstructive mode. At the time of treatments and chemotherapies, narration reconstructs the events passed in their temporality through the present with its critical point and opening a look at the future even if governed by the limits imposed by the disease.

It was a shock in February when they told me something was wrong because it was the second time. Now, it is not a positive period at all, because I have to come here every week for chemotherapy, and it is so hot in August. People go on vacation, but I cannot take my girls to the beach because I have to come here. They will go with a friend of mine (id. 4).

- Search for meaning presents this pattern of changes among the redundant modes:

T1 Generalized mode $\rightarrow$ T2 Externalized mode $\rightarrow$ T3 Externalized mode.

At T1, we find a generalized mode. At the beginning, the narrative experience is not qualified in its subjectivity; in the meaning it can have for the subject the disease is considered as something that is a part of life and is connected to the whole without particular causes and links to oneself. Rather, a general principle is affirmed that allows them to anchor themselves and the perspective meaning of the experience to the shared/cultural/taken for granted dimensions of meaning that make the world traceable to stable mechanisms that govern it.

This is the disease of the century, and like flu there is a case in every family (id. 3).

At T2, the search for meaning mode becomes an externalized mode. The narrative mediating an interpretative connection of the disease is identified outside itself, identifying specific causes in fate, God and in an ungovernable exterior dimension; there are no prospective meanings of the relationship with this experience, which at this stage can be interpreted as a critical event. 
I think we get ill because the environment is ill; the air, the food we eat... I do not see any change in me or in my way of seeing life, only pain (id. 7).

At T3, the redundant mode remains an externalized mode. The narrative of women identifies a link with the experience that is always outside themselves in terms of cause but has questions about the connections with their subjectivity, wondering also what the illness can represent in itself.

I do not think I did anything to deserve such a punishment... maybe it's something that God gives us, a test to make us stronger (id. 8)

- Emotional regulation presents this pattern of changes among the redundant modes:

T1 Pervasive mode $\rightarrow$ T2 Disconnected mode $\rightarrow$ Embodied mode.

At $\mathrm{T} 1$, we find a pervasive mode. This means that the narration of the onset of the disease is dominated by the emotional level in its pregnancy. The woman puts into words invasive emotions related to the uncertainty phase of not knowing yet what she will have to face, configuring the waiting as an emotionally destabilizing critical moment. Narration is then configured as the device that can give voice to the emotional proprium of the crossed phase, i.e., to express through flooding emotional reactions the shock linked to the onset of the disease in one's life.

My thought is fixed in not knowing, waiting, waiting for these certain phases and you are nervous, tense (id. 1).

At $\mathrm{T} 2$, the redundant mode is a disconnected mode. After the communication of the histological report and therefore of the therapeutic treatments to be undertaken, in the narrative we found trajectories of functioning that refer to confusion, distance, and absence of links between emotion and thought. Avoiding, suppressive and defensive mechanisms are narrated by women themselves.

I have no words, nothing comes to my mind (id. 9).

At T3, the mode becomes an embodied mode. Narration during chemotherapy or radiotherapy has the function of putting into words a pain that is now inscribed on the skin; it is physical as well as emotional and presents itself in images. It is the event in its emotional impact that is told in the background of anguish of death. These are intrusive sensorial traces related to the body, its losses, the medications to be applied autonomously, the body image, and the image of oneself. The pharmacological therapies lead to an early menopause and have a series of side effects in relation to which the woman tells of her profound discomfort.

When I'm undergoing radiotherapy and I'm alone with the machine, I look at the ceiling and I am reminded of the images of this treatment: staying there motionless and being used as a sheet on which to write, I felt like a crossword puzzle on which the doctor made signs... the loss of all modesty; my breast, seen by any doctor, is no longer the breast of a good-looking woman, no longer has that aesthetic function. It is more a nuisance, and this hurts me very much (id. 2).

- Organization of self-other relationship presents this pattern of changes among the redundant modes:

T1 Sacrificial mode $\rightarrow$ T2 $->$ Supportive mode $\rightarrow$

\section{T3 Supportive mode.}

At T1, a sacrificial mode emerges. The narrative mediating relationships with others represents them as little children to be protected from this experience; therefore, women tell about the need to hide their emotions.

I have to hide my feelings and show them I'm strong; my children, my husband, my mother and everybody else do not have to worry, they have already suffered a lot (id. 1).

At T2, the mode becomes a supportive mode. Narration builds links between women with breast cancer and others, especially their partner or sisters, who are configured as resources that support, accompany, and make it possible to share and speak about what is happening. Also, their roommates during the hospitalization represent an important source of emotional support and of comparison of the information on how to face the experience.

My partner was always with me, he stayed by my side all the time, he consoled me when it was necessary and encouraged me to think positively when he saw me down (id 10).

At T3, the redundant mode is maintained as a supportive mode. The narration articulates the emotional, practical, and concrete support that women receive at the time of treatment, as it is very heavy and, in some cases, daily; therefore, it requires family organization and a working organization, especially for women with young children, with fundamental help from their partners and mothers. In particular, women report that the others offer important strategies regarding the loss of their hair: with young children, it can become a game, the older children can sustain their own continuity, and friends are there in the moment of shaving.

When I went to the hairdresser, I told my son, and he said to me "Mother I knew it, don't you worry, you're beautiful anyway..." - instead the little one laughs, plays, jokes, teases me, in short you joke about it... in one way or another. Even friends, if they have to choose where to eat pizza, they come here to be with me (id. 1).

- Orientation to action presents this pattern of changes among the redundant modes:

T1 Suspended mode $\rightarrow$ T2 Combative mode $\rightarrow$ T3 Combative mode.

At T1, in which the mode becomes a suspended mode, narration highlights the uncertainty related to its positioning at that moment of the experience, in which the possibility to transform thought into action is not yet accessed and not touching the narrative question.
Narrative and breast cancer 


\section{Figure 1}

For each of the 5 functions that constitute the narrative process of breast cancer experience in women aged under fifty the redundant modes at turning point phases of medical treatments are illustrated: pre-hospitalization (T1); post-operative counselling (T2); adjuvant therapy (T3)

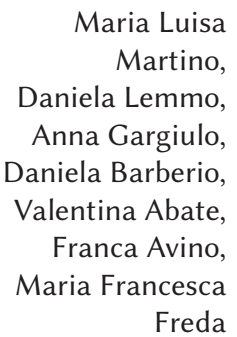

\begin{tabular}{|c|c|c|c|c|c|}
\hline T3 & Reconstructive & Externalized & Embodied & Supportive & Combactive \\
\hline $\mathrm{T} 2$ & Reconstructive & Externalized & Disconnected & Supportive & Combactive \\
\hline $\mathrm{T} 1$ & Chronicled & Generalized & Pervasive & Sacrificial & Suspended \\
\hline & $\begin{array}{l}\text { Organization } \\
\text { of temporality }\end{array}$ & $\begin{array}{c}\text { Search } \\
\text { for meaning }\end{array}$ & $\begin{array}{l}\text { Emotional } \\
\text { regulation }\end{array}$ & $\begin{array}{l}\text { Organization } \\
\text { self-other } \\
\text { relationship }\end{array}$ & $\begin{array}{c}\text { Orientation } \\
\text { to action }\end{array}$ \\
\hline
\end{tabular}

I can talk about it now, but then, we have to see if I have the strength to do it; it depends on what will be (id. 1).

At T2, the mode becomes a combative mode. Narration mediates a relationship between herself and the action; there is a combative orientation that takes on an imperative meaning, linked to the need to respond in an active manner in order to cope with the treatment she will receive. In the second phase of cancer treatment, the narration highlights the importance for the women of being active in order to move forward.

You have to fight, you have to keep going. I get up in the morning and say I have to move on. You just have to face things, you cannot afford to break down (id. 5).

At T3, the combative mode is also linked to the maintenance of a dimension in which to be active over time.

The only thing that is needed is strength; if you are not strong, you do not go forward. I have to be resolute because taking pills every night for 5 years is so annoying (id. 4).

\section{DISCUSSION}

The present study offers a longitudinal view on the redundant modes with which the narrative functions of the meaning-making process of breast cancer experience in women below 50 years old are articulated in the three phases of medical treatment.
Observing the quality of these transformations through repeated narration of the three phases, we have found and interpreted the natural meaningmaking process that each function goes through in the evolution of a natural way according to the experience.

These evolutions allow us to show both an operation that is transformed into integrated modes of construction of connections between the levels of experience and an operation that can cross critical situations and moments of block of construction of connections in certain phases.

In terms of organization of temporality, we identify a narrative evolution which, starting from the first phase, focused on the present punctuated by the chronicles of medical visits, unfolds in the other two phases through the reconstruction of parts of the experience that begin to integrate with each other. The process of searching for meaning in the event and of a relationship between the self and event, moving from a general mode to an externalized mode in the other two phases, signals the transformation of vagueness, which does not qualify the expression in its subjectivity, in a disambiguation whereby an external connection between oneself and the experience in progress is identified.

With respect to the emotional regulation function, we point out a pervasive modality that meets a moment of disconnection in the second phase and then evolves into an embodied mode in the third phase. 
This highlights that at the onset of the disease, the only possible connections occur between the emotion in its raw state and the words. In the phase of communication of the histological report, the emotional regulation function develops in a disconnected modality where the emotional flood is separated from thought as a defensive instinct; thus, it is not possible to find words for the emotional state of shock that is felt in having to start chemotherapy, a piece of news that blunts the mind. In the third phase, the function is established on the body to express the physical and mental pain inscribed in the operated body and subject to medical and pharmacological therapies.

The organization of self-other is a sacrificial way of hiding one's emotions for the well-being of others; it tends to carry on up to increasingly supportive ways for the self in the important postoperative and adjuvant therapy phases in which the others perform important roles of emotional and practical support. Finally, the orientation to actions/decision expresses a trend that from a suspension of one's possible positioning in the course of experience evolves into a mode of coping.

On the one hand, these narrative functions, intended as markers of the experience process, signal a natural progression in which the narrative device activates specific psychic functions in each phase of the experience; they tend towards the integration and construction of an internal synthesis of meanings between the self and the world, which activates in the course of the experience strategies to face the disease, which were initially unexplored.

On the other hand, these markers invite us to reflect on the most critical modes, which tend to be stiffening and to crystalize, representing risks. Specifically, as presented in the graph through a broken line with respect to the continuous arrows, in the transition from $\mathrm{T} 1$ to $\mathrm{T} 2$, we note an inability to operate the emotional regulation that is interrupted in the disconnection mode. This result allows us to highlight the critical issues in constructing the link between emotions and events in the moment of communication of the histological report and therefore the beginning of invasive and long-lasting therapies with important physical and emotional implications for a young woman who experiences early menopause. These kinds of markers, though founded on defensive modalities able to build subjective ways to survive the experience, also represent indicators of rigid structures of relationship with the events that are likely to remain during the crossing of different times of treatment, risking affecting the quality of life and the concordance with treatment.

Observing also the specific aspects of each single phase of the medical treatment, it can be noted that not all the phases of the illness lived in an equal way in young women. It is possible to identify which phases of breast cancer treatment appear to be more critical for women below 50 years old from a clinical point of view. In our study, the moment of the onset of the diagnosis is configured as the phase that registers a psychic functioning still devoid of connections between itself and the experience in all its functions.

We therefore interpret this work as the possibility of identifying narrative markers in their resource and risk abilities, promoting integration between the synchrony of the medical experience and the diachrony of the subjective experience of women. In our opinion, this union is fruitful to support resources for dealing with the adaptation to the various challenges that the treatment phases present.

\section{CONCLUSIONS}

In conclusion, we believe that the narrative device fulfills different modes of psychic functioning within each phase of the breast cancer medical treatment and makes it possible to highlight risk elements for women below 50 years old by identifying the moment in which they can develop.

First of all, we want to reflect on the use of the narrative interview. The interview turned out to be both an exploratory tool, as used in research, and a diachronic narrative assessment device capable of giving the clinician a trend in the relationship between psychic functioning and ongoing experience. With the interview, analyzing narrative functions serves as a diachronic map of the relationship with experience, which, in terms of future development, can be used by giving it a prognostic value, on the one hand, and risk prevention on the other hand.

This study's limitations are related to the number of narrative groups, which does not allow the results to be generalized. This study proposes an in-depth vision of the individual narratives and favors a longitudinal vision. The ad hoc data analysis methodology and the narrative interview represent an original and innovative product of this study that will need further studies to validate the method terms.

Therefore, in the evolution of our research, it will be useful to enlarge the sample and proceed to the construction of statistical trajectories and profiles based on the crossing with external outcome indicators, in order to construct a personalized narrative intervention practice in order to promote well-being support or to activate clinical pathway estimates.

\section{References}

Angus, L., \& McLeod, J. (2004). The handbook of narrative and psychotherapy: Practice, theory and research. Sage.

Bion, W. R. (1962). Apprendere dall'esperienza [Learning from experience]. Armando.
Narrative and breast cancer 
Bolton, G., \& Isaacs, A. (2018). Women's experiences of cancer-related cognitive impairment, its impact on daily life and care received for it following treatment for breast cancer. Psychology, Health \& Medicine, 23, 1261-1274. https://doi.org/10.1080/ 13548506.2018 .1500023

Bonanno, G. A., Wortman, C. B., \& Nesse, R. M. (2004). Prospective patterns of resilience and maladjustment during widowhood. Psychology and Aging, 19, 260-271. https://doi.org/10.1037/0882-7974.19.2.260

Maria Luisa Martino, Daniela Lemmo, Anna Gargiulo, Daniela Barberio, Valentina Abate, Franca Avino, Maria Francesca Freda
Brockmeier, J. (2000). Autobiographical time. Narrative Inquiry, 10, 51-73. https://doi.org/10.1075/ni.10. 1.03bro

Brockmeier, J. (2009). Reaching for meaning: Human agency and the narrative imagination. Theory \& Psychology, 19, 213-233. https://doi.org/10.1177/ 0959354309103540

Cordova, M. J., Andrykowski, M. A., Kenady, D. E., McGrath, P. C., Sloan, D. A., \& Redd, W. H. (1995). Frequency and correlates of posttraumatic-stressdisorder-like symptoms after treatment for breast cancer. Journal of Consulting and Clinical Psychology, 63, 981-986. https://doi.org/10.1037//0022-006x. 63.6.981

Cordova, M. J., Giese-Davis, J., Golant, M., Kronenwetter, C., Chang, V., \& Spiegel, D. (2007). Breast cancer as trauma: Posttraumatic stress and posttraumatic growth. Journal of Clinical Psychology in Medical Settings, 14, 308-319. https://doi.org/10.1007/ s10880-007-9083-6

De Luca Picione, R. (2020a). The semiotic paradigm in psychology. A mature weltanschauung for the definition of semiotic mind. Integrative Psychological and Behavioral Science, 54, 639-650. https:// doi.org/10.1007/s12124-020-09555-y

De Luca Picione, R. (2020b). La proposta dell'Idiographic Science. Discussione degli assunti teorici, epistemologici e metodologici di un possibile approccio idiografico in psicologia [The Idiographic Science proposal. Discussion of the theoretical, epistemological and methodological assumptions of a possible idiographic approach in psychology]. Ricerche in Psicologia, 44, 389-432. https://doi. org/10.3280/RIP2020-00200

De Luca Picione, R., Martino, M. L., \& Troisi, G. (2019). The semiotic construction of the sense of agency. The modal articulation in narrative processes. Integrative Psychological and Behavioral Science, 53, 431-449. https://doi.org/10.1007/s12124-0199475-9

Di Giacomo, D., Cannita, K., Ranieri, J., Cocciolone, V., Passafiume, D., \& Ficorella, C. (2016). Breast cancer and psychological resilience among young women. Journal of Psychopathology, 22, 191-195.

Esposito, G, Ribeiro, A. P., Alves, D., Goncalves, M. M., \& Freda, M. F. (2017). Meaning co-construction in group counselling: the development of innovative moments. Journal of Constructivist Psychology, 30,
404-426. https://doi.org/10.1080/10720537.2016.12 38789

Gillies, J., \& Neimeyer, R. A. (2006). Loss, grief, and the search for significance: Toward a model of meaning reconstruction in bereavement. Journal of Constructivist Psychology, 19, 31-65. https://doi.org/ 10.1080/10720530500311182

Goula, I., Alikari, V., Charalampous, G., Tzavella, F., Zyga, S., Tsironi, M., \& Theofilou, P. (2020). Social support and quality of life in Greek women with breast cancer during chemotherapy and two years later. Health Psychology Report, 2, 98-106, https://doi.org/10.5114/hpr.2020.93757

Greenberg, L., Elliott, R., \& Rice, L. (1993). Facilitating emotional change. Guilford.

Gurevich, M., Devins, G. M., \& Rodin, G. M. (2002). Stress response syndromes and cancer: Conceptual and assessment issues. Psychosomatics, 43, 259-281. https://doi.org/10.1176/appi.psy.43.4.259

Hall, J. M. (2011). Narrative methods in a study of trauma recovery. Qualitative Health Research, 21, 3-13. https://doi.org/10.1177/1049732310377181

Helms, R. L., O’Hea, E. L., \& Corso, M. (2008). Body image issues in women with breast cancer. Psychology, Health \& Medicine, 13, 313-325. https:// doi.org/10.1080/13548500701405509

IHME (2018). Global Burden of Disease Study 2017. Institute for Health Metrics and Evaluation.

Janoff-Bulman, R. (2004). Posttraumatic growth: Three explanatory models. Psychological Inquiry, 15, 30-34.

Jones, S. L., Hadjistavropoulos, H. D., \& Gullickson, K. (2014). Understanding health anxiety following breast cancer diagnosis. Psychology, Health \& Medicine, 19, 525-535. https://doi.org/10.1080/ 13548506.2013 .845300

Joseph, S., \& Linley, P. A. (2005). Positive adjustment to threatening events: an organismic valuing theory of growth through adversity. Review of General Psychology, 9, 262-280. https://doi.org/ 10.1037/1089-2680.9.3.262

Lemmo, D., Martino, M. L., Nunziante Cesàro, A., \& Solbakk, J. H. (2020). Idiosyncratic ambivalence: a three-dimensional interpretative model to understand the non-adhesion of women to breast and cervical cancer screening. Mediterranean Journal of Clinical Psychology, 8, 3, 1-19. https://doi. org/10.6092/2282-1619/mjcp-2563

Martino, M. L., De Luca Picione, R., Lemmo, D., Bolursier, V., \& Freda, M. F. (2019a). Meaning-making trajectories of resilience in narratives of adolescents with multiple sclerosis. Mediterranean Journal of Clinical Psychology, 7, 1-25. https://doi. org/10.6092/2282-1619/2019.7.2049

Martino, M. L., Gargiulo, A., Lemmo, D., Dolce, P., Barberio, D., Abate, V., Avino, F., \& Tortriello, R. (2019b). Longitudinal effect of emotional processing on psychological symptoms in women un- 
der 50 with breast cancer. Health Psychology Open, 6, 1-9. https://doi.org/10.1177/20551029198445

Martino, M. L., Lemmo, D., Gargiulo, A., Barberio, D., Abate, V., Avino, F., \& Tortoriello, R. (2019c). Underfifty women and breast cancer: Narrative markers of meaning-making in traumatic experience. Frontiers in Psychology, 10, 618. https://doi.org/10.3389/ fpsyg.2019.00618

McAdams, D. P. (2008). Personal narratives and the life story. In O. P. John, R. W. Robins, \& L. A. Pervin (Eds.), Handbook of personality: Theory and research (pp. 242-262). The Guilford Press.

Neimeyer, R. A. (2004). Fostering posttraumatic growth: a narrative elaboration. Psychological Inquiry, 15, 53-59.

Neimeyer, R. A. (2006). Complicated grief and the quest for meaning: a constructivist contribution. Journal of Death and Dying, 52, 37-52. https://doi. org/10.2190/EQL1-LN3V-KNYR-18TF

Neimeyer, R. A., Burke, L. A., Mackay, M. M., \& van Dyke Stringer, J. G. (2010). Grief therapy and the reconstruction of meaning: From principles to practice. Journal of Contemporary Psychotherapy, 40, 73-83. https://doi.org/10.1007/s10879-009-9135-3

Pennebaker, J. W., Mayne, T. J., \& Francis, M. E. (1997). Linguistic predictors of adaptive bereavement. Journal of Personality and Social Psychology, 72, 863871. https://doi.org/10.1037//0022-3514.72.4.863

Piaget, J. (1964). Cognitive development in children: Piaget development and learning. Journal of $R e$ search in Science Teaching, 2, 176-186. https://doi. org/10.1002/tea.3660020306

Quattropani, M. C., Lenzo, V., Baio, M., Bordino, V., Germanà, A., Grasso, D., Grisolia, E., Indelicato, F., Manzone, R., \& Pennica, S. (2017). Credenze metacognitive e strategie di coping in operatori di cure domiciliari a rischio di burnout [Metacognitive beliefs and coping strategies in home care providers at risk of burnout]. Psicologia della Salute, 2, 121-142. https://doi.org/10.3280/pds2017-002006

Rainone, N., Chiodi, A., Lanzillo, R., Magri, V., Napolitano, A., Morra, V. B., Valerio, P., \& Freda, M. F. (2017). Affective disorders and health-related quality of life (HRQoL) in adolescents and young adults with multiple sclerosis (MS): The moderating role of resilience. Quality of Life Research, 26, 727-736. https://doi.org/10.1007/s11136-016-1466-4

Rasmussen, D. M., \& Elverdam, B. (2007). Cancer survivors' experience of time: Time disruption and time appropriation. Journal of Advanced Nursing, 57, 614-622. https://doi.org/10.1111/j.1365-2648. 2006.04133.x

Rimè, B. (2009). Emotion elicits the social sharing of emotion: Theory and empirical review. Emotion Review, 1, 60-85. https://doi.org/10.1177/17540739 08097189

Salvatore, S. (2016). Psychology in black and white. The project of a theory-driven science. Information Age.
Salvatore, S., \& Valsiner, J. (2011). Idiographic science as a non-existing object: The importance of the reality of the dynamic system. In S. Salvatore, J. Valsiner, J. Travers Simon, \& A. Gennaro (Eds.), YIS: Yearbook of idiographic science (Vol. 3, pp. 7-26). Firera.

Santaniello, A., Dicé, F., Carratù, R. C., Amato, A., Fioretti, A., \& Menna, L. F. (2020). Methodological and terminological issues in animal-assisted interventions: an umbrella review of systematic reviews. Animals, 10, 759. https://doi.org/10.3390/ ani 10050759

Sherman, D. K., \& Cohen, G. L. (2006). Psychology of self-defense: Self-affirmation theory. Advances in Experimental Social Psychology, 38, 183-242. https://doi.org/10.1016/S0065-2601(06)38004-5

Smorti, A., \& Fioretti, C. (2016). Why narrating changes memory: a contribution to an integrative model of memory and narrative processes. Integrative Psychological and Behavioral Science, 50, 296-319. https://doi.org/10.1007/s12124-015-9330-6

Tronick, E. (2010). Multilevel meaning making and dyadic expansion of consciousness theory: The emotional and the polymorphic polysemic flow of meaning. In D. Fosha, D. J. Siegel, \& M. Solomon (Eds.), The healing power of emotion (pp. 86-111). W. W. Norton \& Co.

Valsiner, J. (2014). An invitation to cultural psychology. Sage.

Villani, D., Cognetta, C., Toniolo, D., Scanzi, F., \& Riva, G. (2016). Engaging elderly breast cancer patients: The potential of e-health interventions. Frontiers in Psychology, 7, 1825. https://doi. org/10.3389/fpsyg.2016.01825

Waters, T. E. A., Shallcross, J. F., \& Fivush, R. (2013). The many facets of meaning-making: Comparing multiple measures of meaning-making and their relations to psychological distress. Memory, 21, 111124. https://doi.org/10.1080/09658211.2012.705300

Winnicott, D. W. (1945). Lo sviluppo emozionale primario [The development of primary emotional state]. Martinelli.
Narrative and breast cancer 